\title{
Site-Selective Cu Deposition on Pt Dendrimer-Encapsulated Nanoparticles: Correlation of Theory and Experiment
}

\author{
Emily V. Carino, ${ }^{\dagger, \ddagger}$ Hyun You Kim, ${ }^{\dagger, \S, \|}$ Graeme Henkelman, ${ }^{\dagger, \S, \|, *}$ and Richard M. Crooks $*, \dagger, \ddagger, \S$ \\ ${ }^{\dagger}$ Department of Chemistry and Biochemistry, ${ }^{\ddagger}$ Center for Electrochemistry, ${ }^{\S}$ Texas Materials Institute, and ${ }^{\|}$Institute for \\ Computational and Engineering Sciences, The University of Texas at Austin, 1 University Station, A5300 Austin, Texas 78712-0165, \\ United States
}

\section{Supporting Information}

ABSTRACT: The voltammetry of $\mathrm{Cu}$ underpotential deposition (UPD) onto Pt dendrimer-encapsulated nanoparticles (DENs) containing an average of 147 $\mathrm{Pt}$ atoms $\left(\mathrm{Pt}_{147}\right)$ is correlated to density functional theory (DFT) calculations. Specifically, the voltammetric peak positions are in good agreement with the calculated energies for $\mathrm{Cu}$ deposition and stripping on the $\mathrm{Pt}(100)$ and $\mathrm{Pt}(111)$ facets of the DENs. Partial $\mathrm{Cu}$ shells on $\mathrm{Pt}_{147}$ are more stable on the $\mathrm{Pt}(100)$

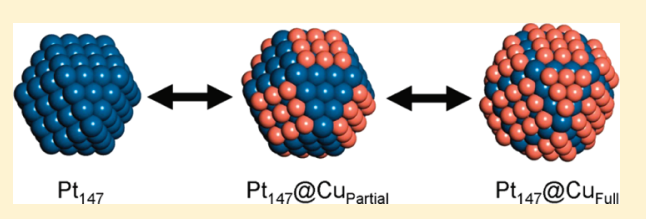
facets, compared to the $\mathrm{Pt}(111)$ facets, and therefore, Cu UPD occurs on the 4-fold hollow sites of Pt(100) first. Finally, the structures of Pt DENs having full and partial monolayers of $\mathrm{Cu}$ were characterized in situ by X-ray absorption spectroscopy (XAS). The results of XAS studies are also in good agreement with the DFT-optimized models.

\section{INTRODUCTION}

In this paper we show that underpotential deposition (UPD) of a $\mathrm{Cu}$ shell onto 1.7-nm-diameter Pt dendrimer-encapsulated nanoparticles (DENs) ${ }^{1-3}$ synthesized within sixth-generation, hydroxyl-terminated (G6-OH) poly(amidoamine) (PAMAM) dendrimers occurs via a two-step process corresponding to facet-specific deposition (Scheme 1). Specifically, we compared

\section{Scheme 1}

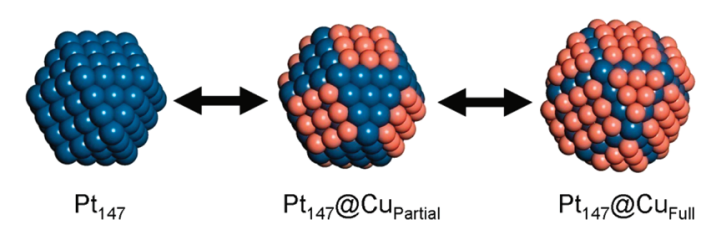

data obtained using first-principles computations with experimental electrochemical and in situ spectroscopic studies of the deposition and stripping of a $\mathrm{Cu}$ shell on Pt DENs consisting of an average of just $\sim 147$ atoms, denoted $\mathrm{G} 6-\mathrm{OH}\left(\mathrm{Pt}_{147}\right)$. The results indicate that $\mathrm{Cu}$ deposits first onto the $\mathrm{Pt}(100)$ facets of $\mathrm{G} 6-\mathrm{OH}\left(\mathrm{Pt}_{147}\right)$, followed by deposition onto the $\mathrm{Pt}(111)$ facets. These findings are significant for the following three reasons. First, we demonstrate that DENs provide a good nanoparticle model for direct comparison of experimental and theoretical findings. This is because they are large enough to characterize experimentally but contain few enough atoms to enable DFT calculations. Second, it is remarkable that UPD can be used to preferentially deposit a partial shell of $\mathrm{Cu}$ on individual facets consisting of just $16 \mathrm{Pt}$ atoms. This level of precision provides a route for directly correlating first-principles calculations to complex, but well-defined, nanoparticles consisting of small numbers of atoms. Third, we demonstrate that results from density functional theory (DFT) provide mechanistic insights into the UPD process that are highly correlated to the shape of cyclic voltammograms (CVs) for Cu UPD onto Pt DENs.

We have previously shown that UPD of $\mathrm{Cu}$ onto $\mathrm{Au}$ and $\mathrm{Pt}$ DENs can be used as a synthetic route to core@shell nanoparticles. ${ }^{4,5}$ In this approach, monometallic DENs consisting of $\mathrm{Au}$ or $\mathrm{Pt}$ were synthesized and immobilized onto electrodes, and a $\mathrm{Cu}$ shell was deposited via UPD. This resulted in $\mathrm{Au} @ \mathrm{Cu}$ or Pt@Cu DENs. With regard to the Au@ $\mathrm{Cu}$ DENs, we found that the $\mathrm{Cu}$ shell could be galvanically exchanged for Pt and that the resulting Au@Pt DENs were electrocatalytically active for the oxygen reduction reaction (ORR). ${ }^{4}$ In the case of Pt@Cu DENs, we examined UPD of $\mathrm{Cu}$ onto three different sizes of Pt DEN cores. CVs for $\mathrm{Cu}$ UPD onto the largest of these, G6-OH $\left(\mathrm{Pt}_{225}\right)$, revealed two well-defined reduction waves, suggesting that deposition of the $\mathrm{Cu}$ shell takes place in two steps. ${ }^{5}$ Pt nanoparticles composed of 225 atoms can form closed-shell truncated octahedra, which are face-centered cubic (fcc) crystal structures presenting $\operatorname{Pt}(100)$ and $\operatorname{Pt}(111)$ facets. ${ }^{6}$ Therefore, we considered that the two voltammetric waves observed during Cu UPD might correspond to discrete deposition onto these two different orientations. This study also suggested that $\mathrm{Cu}$ deposition does not occur on edge or corner atoms of the Pt core. ${ }^{5}$

There is extensive literature relating to $\mathrm{Cu}$ UPD onto welldefined Pt surfaces. ${ }^{7-10}$ One key result to emerge from this literature is that $\mathrm{Cu}$ UPD is more energetically favorable on the $\operatorname{Pt}(100)$ surface compared to $\operatorname{Pt}(111){ }^{8,9}$ This is due to the lower coordination of $\mathrm{Pt}$ atoms on the (100) surface as compared to the close-packed (111) orientation. ${ }^{10}$ There are also several very interesting reports involving $\mathrm{Cu}$ UPD onto stepped Pt surfaces that are highly relevant to UPD onto

Received: September 27, 2011

Published: February 22, 2012 
nanoparticles. ${ }^{11-15}$ For example, a $\mathrm{Pt}(311)$ surface is composed of terraces having two rows of (111) atoms separated by (100) monatomic steps. On this surface it was found that UPD occurs first on the (111) terraces and then on (100) step sites. ${ }^{8} \mathrm{~A}$ related study focused on the opposite case: Pt surfaces with (111) steps and (100) terraces. ${ }^{10}$ Here it was found that $\mathrm{Cu}$ UPD occurred first on the (100) terraces. Clearly, results of this type are related to the $\sim 1.7 \mathrm{~nm}$ DENs discussed here, which have facets comprised of just 16 and 10 atoms in the (100) and (111) orientations, respectively.

A number of studies predating our work have described the UPD of metal shells onto nanoparticles that are substantially larger $(4-20 \mathrm{~nm})^{16-23}$ than the $1.7 \mathrm{~nm}$ DENs reported here. For example, Adzic and co-workers deposited full Pt shells onto PdCo alloy nanoparticles having diameters of $4.6 \mathrm{~nm}$. These nanoparticles were synthesized by UPD of $\mathrm{Cu}$ onto a PdCo core, followed by galvanic exchange of $\mathrm{Cu}$ for Pt. The authors found that the portions of the Pt shell that resided on the (111) orientation of the PdCo core were the most active for the ORR. $^{21}$

Several studies have reported the synthesis of partial (submonolayer) shells on nanoparticles using alternative (non-UPD) means of shell deposition. For example, SanchezCortes and co-workers chemically reduced submonolayer quantities of Pt onto $15 \mathrm{~nm} \mathrm{Au}$ nanoparticles and found that the $\mathrm{Pt}$ shell preferentially formed submonolayer islands oriented in the (111) direction. ${ }^{23}$ Adzic and co-workers have also synthesized $\mathrm{Pt}$ submonolayers on commercially available $2.5 \mathrm{~nm} \mathrm{Ru}$ nanoparticles. ${ }^{19}$ In this case, the Pt submonolayer was formed via spontaneous electroless deposition of $\mathrm{Pt}$ on the surface of the Ru nanoparticles. This resulted in a partial shell constituting approximately 1/9 monolayer of Pt. Finally, Feliu and co-workers showed that hydroquinone adlayers reversibly adsorb onto the $\mathrm{Pt}(111)$ facets of $6 \mathrm{~nm}$ Pt nanoparticles, but irreversible adsorption occurs on $\mathrm{Pt}(100)$ and $\mathrm{Pt}(110)$ facets. ${ }^{24}$

In the present study, we provide experimental and computational evidence that UPD of $\mathrm{Cu}$ onto $\mathrm{G6}-\mathrm{OH}\left(\mathrm{Pt}_{147}\right)$ DENs in a $\mathrm{Cu}^{2+}$-containing $0.10 \mathrm{M} \mathrm{H}_{2} \mathrm{SO}_{4}$ electrolyte occurs in two steps: first onto the Pt(100) facets and then onto Pt(111). The Pt@ $\mathrm{Cu}$ DENs with full and partial $\mathrm{Cu}$ shells were prepared via $\mathrm{Cu}$ UPD onto G6-OH $\left(\mathrm{Pt}_{147}\right)$. The full and partial shell structures were characterized by voltammetry and in situ X-ray absorbance spectroscopy (XAS), and the experimental results are compared with computational models generated using DFT and molecular dynamics (MD) simulations. We find that DFTcalculated binding energies for $\mathrm{Cu}$ on the $\mathrm{Pt}(100)$ and $\mathrm{Pt}(111)$ facets of a "solvated" nanoparticle model, in which $\mathrm{SO}_{4}$ ligands adsorb to the surface to mimic the solvent-surface interactions used in the experiments, correspond well with peaks observed in the CVs of $\mathrm{Cu}$ UPD onto G6-OH( $\left(\mathrm{Pt}_{147}\right)$ DENs. In contrast, the same calculations performed on a naked, $\mathrm{SO}_{4}$-free (solventfree) nanoparticle model did not fit the electrochemical data. Finally, XAS results confirmed that the partial $\mathrm{Cu}$ shell is more stable on the $\operatorname{Pt}(100)$ facet, as opposed to the $\mathrm{Pt}(111)$ facet, in accordance with predictions from DFT.

\section{EXPERIMENTAL SECTION}

Chemicals and Materials. G6-OH dendrimers were purchased from Dendritech, Inc. (Midland, MI) as $5.0 \mathrm{wt} \%$ solutions in methanol. Prior to use, the methanol was removed under vacuum and the dendrimers were redissolved in sufficient water to yield a $0.10 \mathrm{mM}$ solution. Unless otherwise noted, Millipore water (Milli-Q Gradient $\mathrm{PF}-06073$ ) was used to prepare all aqueous solutions. $\mathrm{K}_{2} \mathrm{PtCl}_{4}, \mathrm{CuSO}_{4}$,
$\mathrm{LiClO}_{4}, \mathrm{NaBH}_{4}$, and Ultrex ultrapure $\mathrm{H}_{2} \mathrm{SO}_{4}(18.76 \mathrm{M})$ were purchased from Sigma-Aldrich (Milwaukee, WI). These reagents were used as received without further purification. Two types of working electrodes were used in this study: (1) a 3-mm-diameter, glassy carbon (GC) disk electrode (CH Instruments, Austin, TX) and (2) AvCarb p75 carbon fiber paper (Ballard Materials Products, Lowell, $\mathrm{MA}$ ). A $\mathrm{Hg} / \mathrm{Hg}_{2} \mathrm{SO}_{4}$ reference electrode was purchased from $\mathrm{CH}$ Instruments. Unless otherwise noted, all potentials were measured vs $\mathrm{Hg} / \mathrm{Hg}_{2} \mathrm{SO}_{4}$ but are reported vs $\mathrm{NHE}$ to maintain consistency with the literature. Compressed $\mathrm{Ar}$ (Praxair) was used as received.

Synthesis and Characterization of G6-OH(Pt $\left.{ }_{147} @ \mathrm{Cu}\right)$ DENs. The precise definitions of full- and partial-shell Cu UPD layers will be discussed in the Results and Discussion section, but for now it is sufficient to say that G6-OH $\left(\mathrm{Pt}_{147}\right)$ DENs having maximum $\mathrm{Cu}$ UPD coverage are denoted as $\mathrm{G} 6-\mathrm{OH}\left(\mathrm{Pt}_{147} @ \mathrm{Cu}_{\text {full }}\right)$ and that DENs having less-than-maximum coverage are denoted as G6-OH $\left(\mathrm{Pt}_{147} @ \mathrm{Cu}_{\text {partial }}\right)$.

The synthesis of G6-OH $\left(\mathrm{Pt}_{147} @ \mathrm{Cu}_{\text {full }}\right)$ DENs and subsequent electrochemical measurements using the DEN-modified GC electrodes were made using a polycarbonate flow cell, which enables the exchange of solutions without emersing the electrodes (Supporting Information, Figure S1). Because the electrodes remain in contact with electrolyte while the solutions are exchanged, the working electrode can be maintained under potential control. This is an important provision, because it is necessary to remove free $\mathrm{Cu}^{2+}$ ions from the cell following the synthesis of full and partial shells to prevent them from electrodepositing on the electrode during subsequent electrochemical measurements.

The preparation of G6-OH $\left(\mathrm{Pt}_{147} @ \mathrm{Cu}_{\text {full }}\right)$ DENs on GC electrodes was carried out as previously described. ${ }^{5,25-27}$ Briefly, G6-OH( $\left(\mathrm{Pt}_{147}\right)$ DENs were synthesized in water in two steps. First, 147 equiv of $\mathrm{K}_{2} \mathrm{PtCl}_{4}$ was mixed with 1.0 equiv of $\mathrm{G} 6-\mathrm{OH}$ dendrimer to yield a complex $\left(\mathrm{G} 6-\mathrm{OH}\left(\mathrm{Pt}^{2+}\right)_{147}\right)$. Second, this complex was reduced using a 10 -fold excess of $\mathrm{NaBH}_{4}$ with respect to $\mathrm{Pt}^{2+}$ to yield zerovalent G6$\mathrm{OH}\left(\mathrm{Pt}_{147}\right) \mathrm{DENs}^{28}$ The resulting DENs were then purified by dialysis against water for $24 \mathrm{~h}$.

DENs were immobilized onto the GC working electrodes using a previously described procedure. ${ }^{25,26}$ Briefly, the GC disk electrodes were prepared by successive mechanical polishing with $1.0,0.3$, and $0.05 \mu \mathrm{m}$ alumina, ultrasonicating in a 1:1 water-ethanol mixture for 1 min, and finally electrochemical anodizing in $0.10 \mathrm{M} \mathrm{NaOH} .{ }^{5,29} \mathrm{Next}$, Pt DENs were attached to the GC working electrodes by cycling the potential three times between 0.24 and $1.24 \mathrm{~V}$ in a solution containing the DENs and $0.10 \mathrm{M} \mathrm{LiClO}_{4}$. The DEN-modified GC working electrode, GC counter electrode, and $\mathrm{Hg} / \mathrm{Hg}_{2} \mathrm{SO}_{4}$ reference electrode were then configured in the flow cell. Finally, the surface of the DENs was cleaned using 10 consecutive potential cycles between -0.03 and $1.34 \mathrm{~V}$ in Ar-purged, $0.10 \mathrm{M} \mathrm{H}_{2} \mathrm{SO}_{4}{ }^{5}$

After electrochemical cleaning, the solution was exchanged for Arpurged, $0.10 \mathrm{M} \mathrm{H}_{2} \mathrm{SO}_{4}$ containing $0.010 \mathrm{M} \mathrm{CuSO}_{4}$ by flowing $12.0 \mathrm{~mL}$ of the $\mathrm{Cu}^{2+}$-containing solution through the cell (total cell volume: 1.0 $\mathrm{mL}$ ). Cu UPD and stripping experiments using the DENs-modified $\mathrm{GC}$ electrode were carried out using the following procedure. First, the electrode potential was stepped from the open circuit potential (OCP) to $0.64 \mathrm{~V}$ for $150 \mathrm{~s}$. Second, the potential was swept from 0.64 to 0.84 $\mathrm{V}$, negative to $0.29 \mathrm{~V}$, and then returned to $0.84 \mathrm{~V}$. For some additional experiments relating to the electrochemical properties of G6-OH $\left(\mathrm{Pt}_{147} @ \mathrm{Cu}_{\text {full }}\right)$ and G6-OH $\left(\mathrm{Pt}_{147} @ \mathrm{Cu}_{\text {partial }}\right)$ DENs, the shell was deposited somewhat differently: by stepping, rather than sweeping, the working electrode potential from OCP to $0.29 \mathrm{~V}$, the potential at which a full $\mathrm{Cu}$ shell is deposited on the DENs (denoted $\left.V_{\text {full }}\right)$, and holding the potential there for at least $300 \mathrm{~s} .{ }^{5}$ Next, while continuing to hold the potential at $V_{\text {full }}$, free $\mathrm{Cu}^{2+}$ was removed from the cell by flushing it with $12.0 \mathrm{~mL}$ of Ar-purged, $\mathrm{Cu}^{2+}$-free, $0.10 \mathrm{M}$ $\mathrm{H}_{2} \mathrm{SO}_{4}$. The removal of $\mathrm{Cu}^{2+}$ from the flow cell was confirmed in a separate control experiment (Supporting Information, Figure S2).

Following the syntheses of G6-OH $\left(\mathrm{Pt}_{147} @ \mathrm{Cu}_{\text {full }}\right)$ on GC electrodes via a potential step to $V_{\text {full }}$, the electrodes were used to record CVs in the hydrogen adsorption $\left(\mathrm{H}_{\mathrm{UPD}}\right)$ potential range. This experiment was carried out as follows. Immediately after the synthesis of the $\mathrm{Cu}$-coated DENs and subsequent removal of $\mathrm{Cu}^{2+}$, and without returning to the 
OCP, the cell potential was cycled once from $0.29 \mathrm{~V}\left(V_{\text {full }}\right)$ to $-0.03 \mathrm{~V}$ and back to $0.29 \mathrm{~V}$. Next, the potential was stepped from $V_{\text {full }}$ to a slightly more positive potential, $0.34 \mathrm{~V}$, denoted $V_{\text {partial }}$, and held there for $300 \mathrm{~s}$. Then, while continuing to hold the potential at $V_{\text {partial }}, 12.0$ $\mathrm{mL}$ of fresh $0.10 \mathrm{M} \mathrm{H}_{2} \mathrm{SO}_{4}$ solution was flowed through the cell as described above. The potential was next stepped from $V_{\text {partial }}$ to $0.29 \mathrm{~V}$ and was then cycled again between $0.29 \mathrm{~V}$ and $-0.03 \mathrm{~V}$ to record the $\mathrm{H}_{\mathrm{UPD}}$ on $\mathrm{G6}-\mathrm{OH}\left(\mathrm{Pt}_{147} @ \mathrm{Cu}_{\text {partial }}\right)$ DENs. This procedure was repeated using the following potentials for $V_{\text {partial }}: 0.34 \mathrm{~V}, 0.39 \mathrm{~V}, 0.44 \mathrm{~V}, 0.49$, $0.54 \mathrm{~V}$, and $0.64 \mathrm{~V}$. Lastly, the potential was stepped from $V_{\text {full }}$ to 0.84 $\mathrm{V}\left(V_{\text {bare }}\right)$ and the $\mathrm{H}_{\mathrm{UPD}}$ current was recorded on naked $\mathrm{G} 6-\mathrm{OH}\left(\mathrm{Pt}_{147}\right)$ DENs.

In Situ XAS. The preparation of DEN samples for in situ XAS analysis is discussed elsewhere. ${ }^{5}$ Briefly, however, the AvCarb carbon paper electrodes were rendered hydrophilic by cycling their potentials eight times between $1.64 \mathrm{~V}$ and $-0.37 \mathrm{~V}$ in $0.50 \mathrm{M} \mathrm{H}_{2} \mathrm{SO}_{4}$ before soaking them in solutions of dialyzed $\mathrm{G} 6-\mathrm{OH}\left(\mathrm{Pt}_{147}\right)$ for at least 12 h. ${ }^{5,27}$ The DEN-modified AvCarb electrodes were then configured in a custom-designed cell for in situ XAS experiments. Finally, the DENs were cleaned electrochemically using 10 consecutive potential cycles between -0.15 and $0.84 \mathrm{~V}^{5,27}$

In-situ XAS data were obtained using the DEN-modified AvCarb electrode poised at each of the following three potentials: (1) $V_{\text {full }}=$ $0.26 \mathrm{~V}$ (in the in situ cell); (2) $V_{\text {partial }}=0.41 \mathrm{~V}$, which corresponds to a partial $\mathrm{Cu}$ UPD monolayer; and (3) $V_{\text {bare }}=0.84 \mathrm{~V}$, a potential at which $\mathrm{Cu}$ does not deposit on $\mathrm{G} 6-\mathrm{OH}\left(\mathrm{Pt}_{147}\right)$. These potentials were chosen on the basis of voltammetry corresponding to $\mathrm{Cu}$ stripping from G6-OH $\left(\mathrm{Pt}_{147} @ \mathrm{Cu}_{\text {full }}\right)$ and G6-OH( $\left(\mathrm{Pt}_{147} @ \mathrm{Cu}_{\text {partial }}\right)$ DENs (Supporting Information, Figure S3).

XAS data were acquired as follows. First, spectra were collected at $V_{\text {bare }}$. Second, a full $\mathrm{Cu}$ shell was deposited by stepping the electrode potential from $V_{\text {bare }}$ to $V_{\text {full }}$. Third, the working electrode was taken out of potential control for $\sim 1 \mathrm{~min}$ while the solution was exchanged for $\mathrm{Cu}^{2+}$-free $0.10 \mathrm{M} \mathrm{H}_{2} \mathrm{SO}_{4}$. As mentioned earlier, this prevents free $\mathrm{Cu}^{2+}$ from interfering with the spectrum of the immobilized DENs. Note that we have previously shown that the solution exchange procedure does not compromise the $\mathrm{Cu}$ shells. ${ }^{5}$ Fourth, the cell potential was returned to $V_{\text {full }}$ and held there while XAS spectra were recorded. After collecting XAS spectra with the electrode poised at $V_{\text {full }}$ the potential was stepped from $V_{\text {full }}$ to $V_{\text {partial }}$ and held there while collecting additional XAS scans. Finally, the $\mathrm{Cu}$ shell was removed by sweeping the potential from $V_{\text {partial }}$ to $V_{\text {bare }}$ and additional XAS spectra were collected.

Characterization. Transmission electron microscope (TEM) images were obtained at $200 \mathrm{keV}$ in bright-field mode using a JEOL 2010F TEM. X-ray photoelectron spectroscopy (XPS) spectra were obtained using a Kratos Axis Ultra spectrometer equipped with an $\mathrm{Al}$ $\mathrm{K} \alpha$ radiation source. Spectra were collected at a pass energy of $20 \mathrm{eV}$ and a step size of $0.5 \mathrm{eV}$. CVs using GC electrodes were obtained using a $\mathrm{CHI} 760 \mathrm{~B}$ potentiostat ( $\mathrm{CH}$ Instruments). The in situ XAS experiments were carried out using a WaveNow hand-held potentiostat (Pine Instruments, Grove City, PA).

XAS experiments were performed at beamline X18B of the National Synchrotron Light Source at Brookhaven National Laboratory. In-situ data were obtained with the working electrode under potential control using a previously described spectroelectrochemical cell. ${ }^{5,27}$ The XAS spectra were collected in fluorescence mode using an Ar-filled, fivegrid Lyttel detector, whereas reference spectra were obtained using $\mathrm{Pt}$ and $\mathrm{Cu}$ foils and collected in transmission mode. Prior to being fit, the $\mathrm{X}$-ray absorbance edges for the in situ XAS data were aligned in energy with those for the reference foil spectra. XAS data were analyzed using the IFEFFIT6 sixPACK, ATOMS, and Horae software packages. ${ }^{30-32}$ This software is available at no charge through the Consortium for Advanced Radiation Sources and is accessible online at http://cars9. uchicago.edu/ifeffit/Downloads.

Density Functional Theory Calculations. Four models, shown in Figure 1, were used to study $\mathrm{Cu}$ deposition and stripping on $\mathrm{Pt}$ DENs: (1) a cuboctahedral Pt nanoparticle consisting of $147 \mathrm{Pt}$ atoms, denoted $\mathrm{Pt}_{147}$ DFT $;(2)$ a SO$_{4}$ ligand-covered half-nanoparticle, denoted $\left(\mathrm{SO}_{4}\right) \mathrm{Pt}_{147}$ DFT-half; (3) a nanoparticle model representing the G6-

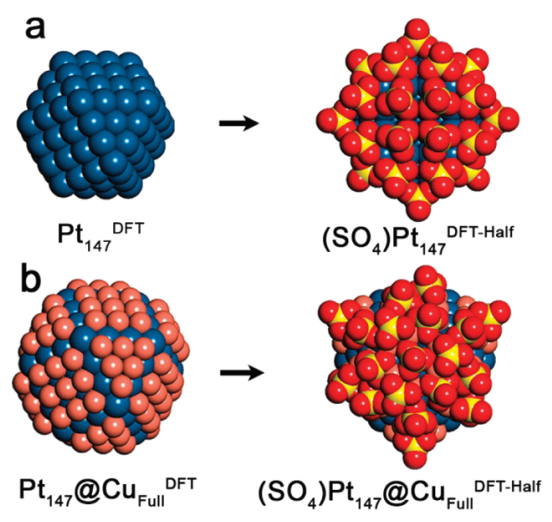

Figure 1. DFT-optimized (a) $\mathrm{Pt}_{147}{ }^{\text {DFT }}$ and $\left(\mathrm{SO}_{4}\right) \mathrm{Pt}_{147}$ DFT-half and (b) $\mathrm{Pt}_{147} @ \mathrm{Cu}_{\text {full }}$ DFT and $\left(\mathrm{SO}_{4}\right) \mathrm{Pt}_{147} @ \mathrm{Cu}_{\text {full }}$ DFT-half models. These models were used in the DFT studies of the $\mathrm{Cu}$ deposition and stripping processes.

$\mathrm{OH}\left(\mathrm{Pt}_{147} @ \mathrm{Cu}_{\text {full }}\right)$ DENs, denoted $\mathrm{Pt}_{147} @ \mathrm{Cu}_{\text {full }}{ }^{\mathrm{DT}}$; and (4) a $\mathrm{SO}_{4}$ ligand-covered half-nanoparticle model, denoted $\left(\mathrm{SO}_{4}\right) \mathrm{Pt}_{147} @$ $\mathrm{Cu}_{\text {full }}$ DFT-half.

The models with $\mathrm{SO}_{4}$ ligands were used to investigate the effect of counterions from the solution on the energetics of $\mathrm{Cu}$ deposition and stripping. Half-nanoparticles were modeled to reduce the computational cost associated with the large number of atoms involved. In test cases of $\mathrm{Cu}$ deposition and stripping, we found that the half-particle approximation changed the binding of $\mathrm{Cu}$ by less than $0.1 \mathrm{eV}$ as compared to the full particle. The $\mathrm{Pt}_{147} @ \mathrm{Cu}_{\text {full }}{ }^{\mathrm{DFT}}$ model contained $102 \mathrm{Cu}$ atoms, 6 and 9 on the $\mathrm{Pt}(111)$ and $\mathrm{Pt}(100)$ facets, respectively. The $\left(\mathrm{SO}_{4}\right) \mathrm{Pt}_{147}$ DFT-half model contained $20 \mathrm{SO}_{4}$ ligands, 3 on each $\mathrm{Pt}(111)$ facet, 4 on the $\mathrm{Pt}(100)$ facet, and 4 on the remaining portion of the $\mathrm{Pt}(111)$ facet. The $\left(\mathrm{SO}_{4}\right) \mathrm{Pt}_{147} @ \mathrm{Cu}_{\text {full }}$ DFT-half model contained $19 \mathrm{SO}_{4}$ ligands: 1 on each $\mathrm{Cu}(111)$ facet, 3 on each $\mathrm{Cu}(100)$ facet, and 9 on the $\mathrm{Pt}-\mathrm{Cu}$ interface.

Calculations of the binding energy of $\mathrm{Cu}$ to the $\mathrm{Pt}$ nanoparticle were compared with the experimental $\mathrm{CV}$ data. The electrochemical potential for depositing $\mathrm{Cu}$ onto the Pt DENs was related to the energy gained by adsorbing a $\mathrm{Cu}$ atom onto the $\mathrm{Pt}_{147}{ }^{\mathrm{DFT}}$ particle, $E_{\text {deposit }}$ Similarly, the stripping potential was related to the energy required to remove a $\mathrm{Cu}$ atom from $\mathrm{Pt}_{147} @ \mathrm{Cu}_{\text {full }}{ }^{\mathrm{DFT}}, E_{\text {Strip }}$. Solvent effects were evaluated by performing the same calculations on the $\mathrm{SO}_{4}$ covered models.

The DFT calculations were carried out in vacuum for computational efficiency, but this means that the solvation free-energy of desorbed species was missing from $E_{\text {deposit }}$ and $E_{\text {strip }}$. Fortunately, the solvation energy of $\mathrm{Cu}^{2+}$ contributes a constant factor in the $\mathrm{Cu}$ adsorption or desorption process, and so it is not required for the calculation of relative binding energies with respect to a reference. Our chosen reference was the binding of $\mathrm{Cu}$ to $\mathrm{Pt}_{147} @ \mathrm{Cu}_{\text {full }}$ DFT $\left(E_{\text {deposit }}\right.$ bulk-DFT $=$ $-2.97 \mathrm{eV}$ ), which we associated with the bulk $\mathrm{Cu}$ reduction potential in the electrochemical experiment, $0.24 \mathrm{~V}$ (Supporting Information, Figure S2). The DFT-calculated electrochemical potentials for the deposition and stripping processes are then defined as $V_{\text {deposit }}$ DFT $=$ $1 / 2\left(E_{\text {deposit }}-E_{\text {deposit }}\right.$ bulk-DFT $)$ and $V_{\text {strip }}$ DFT $=1 / 2\left(E_{\text {strip }}+E_{\text {deposit }}\right.$ bulk-DFT $)$, where the factor of $1 / 2$ accounts for the two electron process.

The structures of the nanoparticle models were optimized with spin-polarized DFT calculations using the Vienna ab initio simulation package (VASP) code. $^{33,34}$ Electronic exchange and correlation were modeled using the PW91 functional. ${ }^{35}$ Valence electron wave functions were expanded in a plane-wave basis up to an energy cutoff of $290 \mathrm{eV}$. The ionic cores were described by the projector augmented-wave (PAW) method. ${ }^{34}$ Nanoparticles were placed on the center of the $(28 \AA)^{3}$ cell. Structures were considered converged when the force on all atoms dropped below $0.02 \mathrm{eV} / \AA$. A Fermi smearing function, with a width of $0.2 \mathrm{eV}$, was used to improve convergence with respect to states near the Fermi level. 
Molecular Dynamics (MD) Simulations. The stability of $\mathrm{Pt}_{147} @$ $\mathrm{Cu}_{\text {full }}{ }^{\mathrm{DT}}$ was evaluated by running MD simulations at $350 \mathrm{~K}$ using the LAMMPS package. ${ }^{36}$ Interatomic forces were evaluated with the embedded atom method (EAM) many-body potential. The MD trajectory was evaluated using a time step of $1 \mathrm{fs}$ for a total simulation time of $300 \mathrm{~ns}$.

\section{RESULTS AND DISCUSSION}

Cu UPD onto G6-OH( $\left(\mathrm{Pt}_{147}\right)$ DENs. We chose to use $\mathrm{Pt}$ DENs consisting of an average of 147 atoms for this study, because this number can result in a closed shell cuboctahedron. This structure has $92 \mathrm{Pt}$ atoms on its surface, arranged in 6 $\mathrm{Pt}(100)$ facets and $8 \mathrm{Pt}(111)$ facets (Scheme 1). Each $\mathrm{Pt}(100)$ facet consists of 16 atoms, and each $\mathrm{Pt}(111)$ facet consists of 10 atoms, with the edge and corner atoms being shared. These DENs have a measured diameter of $1.7 \pm 0.3 \mathrm{~nm}$ (Supporting Information, Figure S4), which is consistent with previous reports and their calculated diameter $(1.6 \mathrm{~nm}){ }^{28}$ Before presenting the results of our study, it is important to introduce a key aspect of the nomenclature that will be used. Specifically, electrochemical potentials and binding energies will be discussed separately, and therefore, different symbols are used for each: electrochemical potentials are referred to using the symbol $V$, and binding energies are denoted as $E$.

The red line in Figure 2 is a $\mathrm{CV}$, which was recorded in 0.10 $\mathrm{M} \mathrm{H}_{2} \mathrm{SO}_{4}$ containing $0.010 \mathrm{M} \mathrm{CuSO}_{4}$, showing $\mathrm{Cu} \mathrm{UPD}$ onto

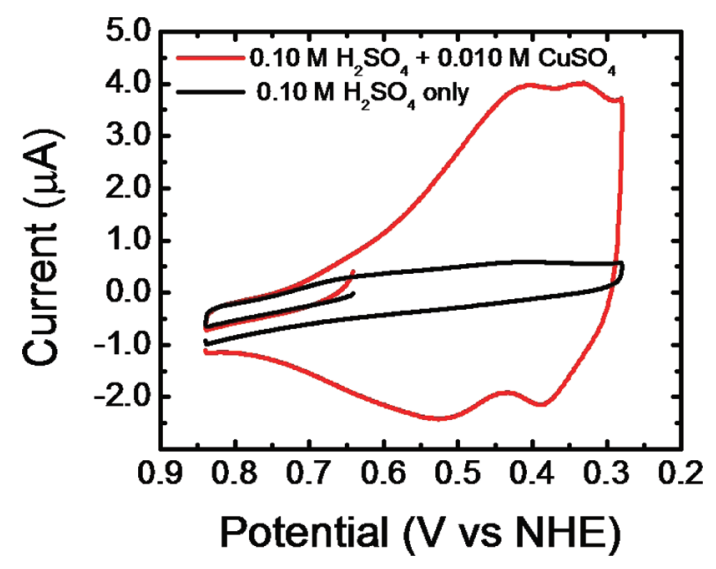

Figure 2. Voltammetry pertaining to a GC electrode modified with G6-OH $\left(\mathrm{Pt}_{147}\right)$ DENs showing Cu UPD and stripping (red) in $0.10 \mathrm{M}$ $\mathrm{H}_{2} \mathrm{SO}_{4}+0.010 \mathrm{M} \mathrm{CuSO}_{4}$ that was deoxygenated with $\mathrm{Ar}$, and the background capacitance (black) in $0.10 \mathrm{M} \mathrm{H}_{2} \mathrm{SO}_{4}$ only, which was also purged with Ar. Both scans began at $0.64 \mathrm{~V}$ and were initially swept in the positive direction at a scan rate of $10 \mathrm{mV} / \mathrm{s}$.

and $\mathrm{Cu}$ stripping from $\mathrm{G} 6-\mathrm{OH}\left(\mathrm{Pt}_{147}\right)$ DENs. Two poorly resolved reduction waves are present at 0.41 and $0.33 \mathrm{~V}$, and these correspond to the deposition of the $\mathrm{Cu}$ shell in two steps. The potential difference between the peaks of these waves, denoted $\Delta V_{\text {deposit }}{ }^{\exp }$, is $0.08 \mathrm{~V}$. Upon scan reversal, two oxidation waves appear at 0.39 and $0.53 \mathrm{~V}$. These correspond to the stripping of $\mathrm{Cu}$ from the $\mathrm{G} 6-\mathrm{OH}\left(\mathrm{Pt}_{147}\right)$ core in two steps. The stripping waves, while also broad, are better resolved than the deposition waves with $\Delta V_{\text {strip }}{ }^{\exp }=0.14 \mathrm{~V}$. The background current (black line, Figure 2), which is capacitive, was obtained under the same conditions as the UPD scan except in the absence of $\mathrm{Cu}^{2+}$.

The peaks representing $\mathrm{Cu}$ UPD on these DENs are not as sharp as those typically observed for Cu UPD on high-quality Pt single-crystal electrodes. This is a consequence of the very small facet sizes on the DENs and the fact that most of the atoms on both the (111) and (100) facets are shared. For example, only a single $\mathrm{Pt}$ atom on the (111) face is unshared (Scheme 1). Similarly broad $\mathrm{Cu}$ peaks have been reported by others for UPD onto nanoparticles. ${ }^{21,37,38}$ Note that lowering the voltammetric scan rate below $10 \mathrm{mV} / \mathrm{s}$ did not change the peak positions or increase their sharpness.

The electrochemical properties of G6-OH $\left(\mathrm{Pt}_{147} @ \mathrm{Cu}_{\text {full }}\right)$ and G6-OH $\left(\mathrm{Pt}_{147}\right)$ DENs in the $\mathrm{H}_{\mathrm{UPD}}$ potential region were examined in $0.10 \mathrm{M} \mathrm{H}_{2} \mathrm{SO}_{4}$ (Supporting Information, Figure $\mathrm{S} 5 \mathrm{a})$. Current due to $\mathrm{H}_{\mathrm{UPD}}$ dominates the $\mathrm{CV}$ of the G6$\mathrm{OH}\left(\mathrm{Pt}_{147}\right)$-modified GC electrode, while this reaction is greatly suppressed on the G6-OH $\left(\mathrm{Pt}_{147} @ \mathrm{Cu}_{\mathrm{full}}\right)$-modified electrode. We have previously shown that similar results are obtained on G6-OH $\left(\mathrm{Pt}_{225}\right)$ DENs with and without a Cu UPD shell. ${ }^{5}$ The results in Figure S5a suggest that G6-OH( $\left(\mathrm{Pt}_{147} @ \mathrm{Cu}_{\text {full }}\right)$ DENs assume a well-segregated core@shell structure.

We also examined $\mathrm{H}_{\mathrm{UPD}}$ on a G6-OH $\left(\mathrm{Pt}_{147} @ \mathrm{Cu}_{\text {partial }}\right)$ modified GC electrode (Supporting Information, Figure S5b). The G6-OH $\left(\mathrm{Pt}_{147} @ \mathrm{Cu}_{\text {partial }}\right)$ DENs were prepared by stripping incrementally greater amounts of the $\mathrm{Cu}$ shell from G6$\mathrm{OH}\left(\mathrm{Pt}_{147} @ \mathrm{Cu}_{\text {full }}\right)$ DENs. Removal of a small fraction of the $\mathrm{Cu}$ shell restores the current for only one of the two $\mathrm{H}$ adsorption peaks. This indicates that partial shells of $\mathrm{Cu}$ suppress $\mathrm{H}_{\text {UPD }}$ on one of the facets but not the other, and it further hints that the $\mathrm{Cu}$ UPD is selective for specific facets. ${ }^{9,10}$ In the next section, we describe how computational models were used to examine the selectivity of the deposition process.

Computational Studies of Cu UPD and Stripping on Pt DENs. An estimate of the potential at which Cu UPD occurs was made by calculating the average binding energy $\left(E_{\text {deposit }}\right)$ of $\mathrm{Cu}$ atoms on the $\mathrm{Pt}(100)$ and $\mathrm{Pt}(111)$ facets of $\mathrm{Pt}_{147}{ }_{\text {DFT }}$ using the $\mathrm{Pt}_{147} @ \mathrm{Cu}_{\text {partial }}$ and $\mathrm{Pt}_{147} @ \mathrm{Cu}_{\text {full }}$ models (Scheme 1). The average binding energy was calculated to be $-3.70 \mathrm{eV}$ on the $\mathrm{Pt}(100)$ facet and $-3.33 \mathrm{eV}$ on the $\mathrm{Pt}(111)$ facet, leading to a calculated shift in potential for deposition on the two facets of $\Delta V_{\text {deposit }}^{\text {DFT }}=0.19$ V. Stronger binding of $\mathrm{Cu}$ on the $\operatorname{Pt}(100)$ facet is consistent with the first (most positive) UPD peak observed in Figure 2, and weaker $\mathrm{Cu}$ binding on the $\mathrm{Pt}(111)$ facet is likewise associated with the second peak. What is not captured in these average binding energy calculations is the difference in potential between deposition and stripping. For that, we require a more detailed atom-by-atom model of the deposition and stripping processes.

The calculated process for $\mathrm{Cu}$ deposition on $\mathrm{Pt}_{147}{ }^{\mathrm{DFT}}$ is shown in Figure 3a (and with more detail in Figure S6 of the Supporting Information). Deposition of $\mathrm{Cu}$ atoms onto the $\mathrm{Pt}(100)$ facet sites is energetically favorable, meaning that the binding energies of the $\mathrm{Cu}$ atoms are more negative compared to the $\mathrm{Pt}(111)$ facets. The binding energies of $\mathrm{Cu}$ atoms on the $\operatorname{Pt}(100)$ facet are similar: $E_{\text {deposit }}=-3.71 \mathrm{eV}$ for the first atom (step 1 in Figure 3a) and $E_{\text {deposit }}=-3.70 \mathrm{eV}$ for subsequent $\mathrm{Cu}$ atoms (Supporting Information, Figure S6). This is again consistent with the association of $\mathrm{Cu}$ deposition on the $\mathrm{Pt}(100)$ facet with the first (most positive) UPD current peak in Figure 2. The observation that the binding energy is similar for each $\mathrm{Cu}$ atom deposited on the $\mathrm{Pt}(100)$ facet demonstrates that $\mathrm{Cu}$ deposition onto the $\mathrm{Pt}(100)$ facet is dominated by $\mathrm{Pt}-\mathrm{Cu}$ interactions.

After the $\mathrm{Pt}(100)$ facets are covered with $\mathrm{Cu}$ atoms, deposition begins on the $\operatorname{Pt}(111)$ facets. The first $\mathrm{Cu}$ atom on the $\operatorname{Pt}(111)$ facet binds with an energy $E_{\text {deposit }}=-3.07 \mathrm{eV}$ (step 3 in Figure 3a). Subsequent binding of $\mathrm{Cu}$ atoms to this 


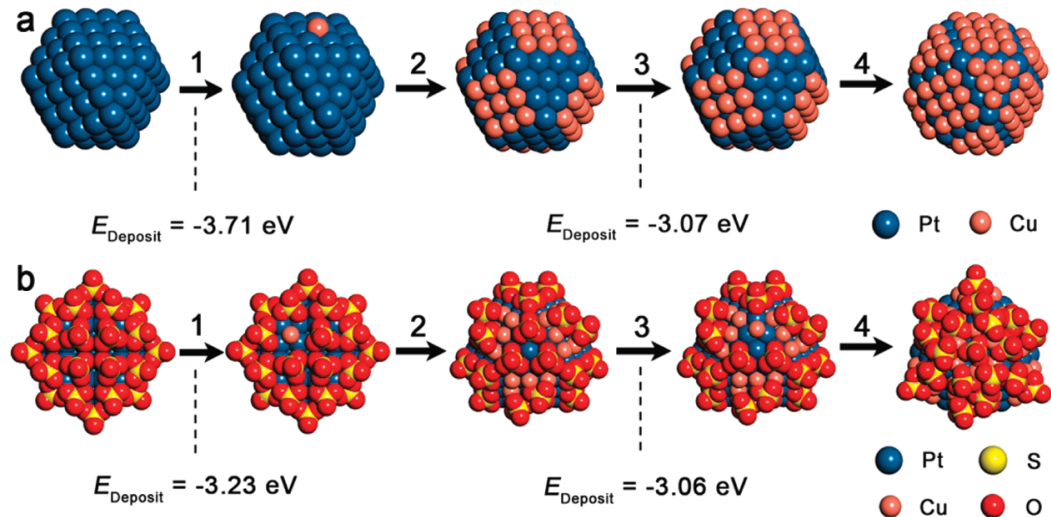

Figure 3. $\mathrm{Cu}$ deposition process shown with the (a) $\mathrm{Pt}_{147}{ }^{\mathrm{DFT}}$ and (b) $\left(\mathrm{SO}_{4}\right) \mathrm{Pt}_{147}$ DFT-half models.

facet is stronger $\left(E_{\text {deposit }}=-3.33 \mathrm{eV}\right)$ (Supporting Information, Figure $\mathrm{S} 6$ ). In other words, the first $\mathrm{Cu}$ deposition event on the $\operatorname{Pt}(111)$ facet is a "peak generating event", because this step induces spontaneous $\mathrm{Cu}$ deposition on the remainder of the facet. We therefore associate the binding energy for the first $\mathrm{Cu}$ atom on the $\operatorname{Pt}(111)$ facet with the location of the second (more negative) $\mathrm{Cu}$ UPD peak in Figure 2. The calculated locations of these peaks are shown in Figure 4 for comparison with the experimental CV data.

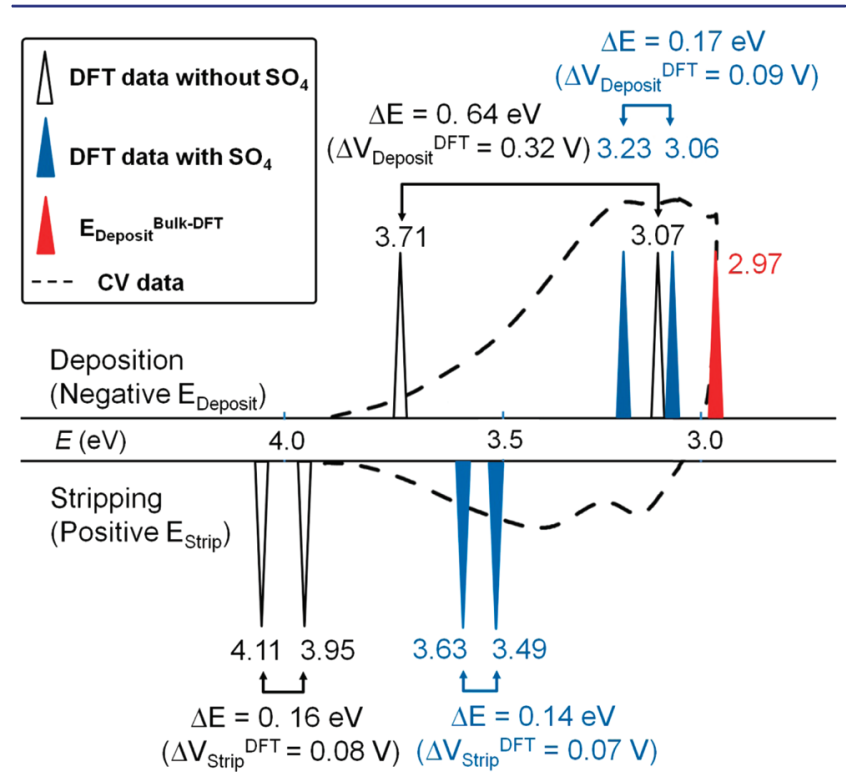

Figure 4. DFT calculated $\mathrm{Cu}$ deposition and stripping energies for the various models with the experimentally obtained Cu UPD CV overlaid for comparison (black dashed line).

The difference in potential for $\mathrm{Cu}$ deposition on the $\mathrm{Pt}(100)$ and $\operatorname{Pt}(111)$ facets, $\Delta V_{\text {deposit }}{ }^{\mathrm{DFT}}=0.32 \mathrm{~V}$, is calculated from the difference in initial binding energy on the two facets (steps 1 and 3 in Figure 3a), taking into account the two-electron transfer required for the reduction of $\mathrm{Cu}^{2+}$. The measured potential difference between the Cu UPD peaks, $\Delta V_{\text {deposit }}{ }^{\exp }=$ $0.08 \mathrm{~V}$, is significantly smaller than the calculated value. Another difference between the calculated and experimental $\mathrm{CV}$ peaks is the so-called "UPD shift", a parameter that describes the magnitude of the potential difference between the potential for $\mathrm{Cu}$ UPD and the bulk $\mathrm{Cu}$ reduction potential. ${ }^{39,40}$ Figure 2 shows the two deposition peaks at 0.41 and $0.33 \mathrm{~V}$, which are close to the experimentally observed bulk $\mathrm{Cu}$ reduction potential, $0.24 \mathrm{~V}$ (Supporting Information, Figure S2). These UPD potentials correspond to shifts, relative to the bulk $\mathrm{Cu}$ reduction potential, of 0.17 and $0.09 \mathrm{~V}$, respectively. The experimentally observed UPD shifts are presented in Table 1 alongside the corresponding UPD shifts calculated by DFT. The DFT calculated UPD shift for $\mathrm{Cu}$ deposition on the $\mathrm{Pt}(100)$ and $\mathrm{Pt}(111)$ facets of $\mathrm{Pt}_{147}{ }^{\mathrm{DFT}}$ are 0.36 and $0.05 \mathrm{~V}$. While the UPD shift calculated for $\mathrm{Cu}$ deposition on $\mathrm{Pt}(111)$ is in reasonable agreement with the experimentally observed value, the UPD shift corresponding to $\mathrm{Cu}$ UPD on the $\mathrm{Pt}(100)$ facet, $0.36 \mathrm{~V}$, is too large compared to the experimental value. In the next section, we will show that this discrepancy can be attributed to solvent interactions with the DEN surface.

The $\mathrm{Cu}$ deposition calculations were repeated using $\mathrm{SO}_{4}$ ligand-covered half-nanoparticle models (Figure 1) to evaluate the sensitivity of the $\mathrm{Cu}$ binding energy calculations to the presence of ligands from solution bound to the nanoparticles. Figure $3 \mathrm{~b}$ shows the key steps in the $\mathrm{Cu}$ deposition process on the $\left(\mathrm{SO}_{4}\right) \mathrm{Pt}_{147}$ DFT-half model. The first step in this process is the desorption of a $\mathrm{SO}_{4}$ ligand from the $\mathrm{Pt}(100)$ facet of $\left(\mathrm{SO}_{4}\right) \mathrm{Pt}_{147}$ DFT-half. This is necessary to create space on the $\mathrm{Pt}$ surface to which $\mathrm{Cu}$ can bind (Figure $3 \mathrm{~b}$, step 1 ). The binding energy of $\mathrm{Cu}$ in this step was found to be $E_{\text {deposit }}=-3.23 \mathrm{eV}$, which is significantly weaker than that calculated for the bare $\mathrm{Pt}_{147}{ }^{\text {DFT }}$ particle $(-3.71 \mathrm{eV})$. The weaker binding energy is due

Table 1. Experimental and DFT-Calculated UPD Deposition and Stripping Potential Shifts Relative to Bulk Cu Deposition

\begin{tabular}{|c|c|c|c|c|c|c|}
\hline & \multicolumn{2}{|c|}{ experimental data } & \multicolumn{4}{|c|}{ DFT-calculated data } \\
\hline deposition & $\operatorname{Pt}(100)$ & $\operatorname{Pt}(111)$ & $\begin{array}{l}\mathrm{Pt}_{147} \text { DFT } \\
\mathrm{Pt}(100)\end{array}$ & $\operatorname{Pt}(111)$ & $\begin{array}{l}\left(\mathrm{SO}_{4}\right) \mathrm{Pt}_{1} \\
\mathrm{Pt}(100)\end{array}$ & $\operatorname{Pt}(111)$ \\
\hline UPD shift & $0.17 \mathrm{~V}$ & $0.09 \mathrm{~V}$ & $\begin{array}{l}0.36 \mathrm{~V} \\
\mathrm{Pt}_{147} @ \mathrm{Cu}\end{array}$ & $0.05 \mathrm{~V}$ & $\begin{array}{l}0.13 \mathrm{~V} \\
\left(\mathrm{SO}_{4}\right) \mathrm{Pt}_{1}\end{array}$ & $\begin{array}{l}0.05 \mathrm{~V} \\
\text { half }\end{array}$ \\
\hline stripping & $\mathrm{Cu}(100)$ & $\mathrm{Cu}(111)$ & $\mathrm{Cu}(100)$ & $\mathrm{Cu}(111)$ & $\mathrm{Cu}(100)$ & $\mathrm{Cu}(111)$ \\
\hline UPD shift & $0.29 \mathrm{~V}$ & $0.15 \mathrm{~V}$ & $0.57 \mathrm{~V}$ & $0.49 \mathrm{~V}$ & $0.33 \mathrm{~V}$ & $0.25 \mathrm{~V}$ \\
\hline
\end{tabular}




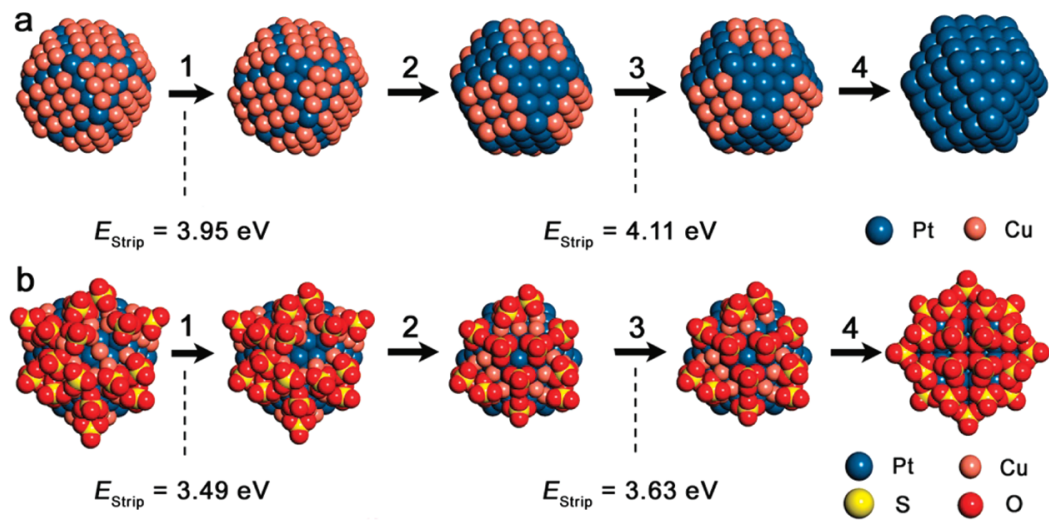

Figure 5. Cu stripping process shown on the (a) $\mathrm{Pt}_{147} @ \mathrm{Cu}_{\text {full }}{ }^{\mathrm{DFT}}$ and $(\mathrm{b})\left(\mathrm{SO}_{4}\right) \mathrm{Pt}_{147} @ \mathrm{Cu}_{\text {full }}$ DFT-half models.

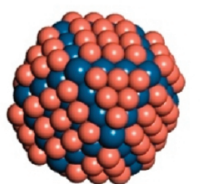

Model F1

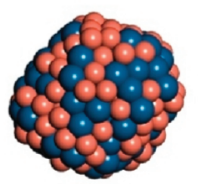

Model F2

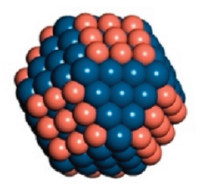

Model P1

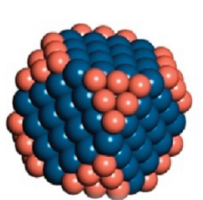

Model P2

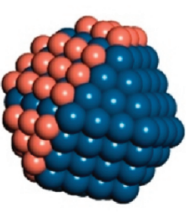

Model P3

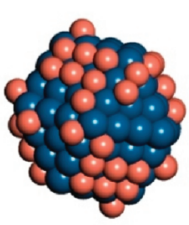

Model P4

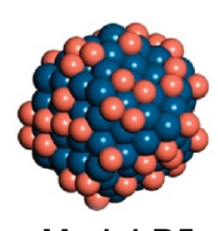

Model P5

Figure 6. Structural models calculated by DFT and MD simulations for the purpose of comparing them to values extracted from fits to the XAS spectra of G6-OH $\left(\mathrm{Pt}_{147} @ \mathrm{Cu}_{\text {full }}\right)$ and $\mathrm{G} 6-\mathrm{OH}\left(\mathrm{Pt}_{147} @ \mathrm{Cu}_{\text {partial }}\right)$. Model F1 is the full shell model generated by the deposition of Cu atoms onto both the $\mathrm{Pt}(100)$ and $\mathrm{Pt}(111)$ facets of $\mathrm{Pt}_{147}{ }^{\mathrm{DFT}}$ as shown in Figure 3; Model F2 is a surface-alloyed structure that resulted when MD simulations were applied to structural model F1; Model P1 is the partial shell model generated by the deposition of $\mathrm{Cu}$ atoms onto only the $\mathrm{Pt}(100)$ facets of $\mathrm{Pt} t_{147} \mathrm{DFT}$ as shown in Figure 3; Model P2 is another partial shell model in which $\mathrm{Cu}$ occupies only the Pt(111) facet positions; Model P3 is a partial shell model in which the $\mathrm{Cu}$ atoms are arranged in a Janus-like partial shell coverage; Model $\mathrm{P} 4$ is a partial shell model having most of the Cu atoms deposited in the $\mathrm{Pt}(100)$ facets and a small degree of dispersion of the $\mathrm{Cu}$ shell atoms to the $\mathrm{Pt}(111)$ facets; Model P5 is a partial shell structure created by randomly distributing $\mathrm{Cu}$ atoms over the entire surface.

to saturation of the dangling $\mathrm{Pt}$ bonds at the surface. After depositing the first $\mathrm{Cu}$ atom, the binding energy of $\mathrm{Cu}$ atoms subsequently placed on the $\mathrm{Pt}(100)$ facet was found to increase, leading to barrierless $\mathrm{Cu}$ deposition on the remaining $\mathrm{Pt}(100)$ facets (Figure $3 b$, step 2 ).

On the $\mathrm{Pt}(111)$ facet, the $\mathrm{SO}_{4}$ ligands are found to have a negligible effect on the initial $\mathrm{Cu}$ binding. This is because the initial binding site (step 3 in Figure $3 \mathrm{~b}$ ) on the small $\mathrm{Pt}(111$ ) facet is not sterically crowded by $\mathrm{SO}_{4}$ ligands. As before, the binding of the first $\mathrm{Cu}$ atom on the $\mathrm{Pt}(111)$ facet lowers the barrier for the deposition of subsequent $\mathrm{Cu}$ atoms on this facet (step 4 in Figure $3 b$ ).

The binding energies and potentials for $\mathrm{Cu}$ UPD onto the $\mathrm{SO}_{4}$-covered Pt DENs are summarized in Figure 4 and Table 1. In the presence of $\mathrm{SO}_{4}$ ligands, the calculated UPD shifts for the $\mathrm{Pt}(100)$ and $\mathrm{Pt}(111)$ facets of the $\left(\mathrm{SO}_{4}\right) \mathrm{Pt}_{147}$ DFT-half model, $V=0.13$ and $0.05 \mathrm{~V}$, respectively, are in good agreement with the corresponding experimental values of $V=0.17$ and $0.09 \mathrm{~V}$.

$\mathrm{Cu}$ stripping was modeled in a manner similar to that described for the UPD process, except the $\mathrm{Cu}$ binding energies were calculated by removing a $\mathrm{Cu}$ atom from the particle surface. The key steps associated with $\mathrm{Cu}$ stripping from the $\mathrm{Pt}_{147} @ \mathrm{Cu}_{\text {full }}$ DFT model are shown in Figure 5a. The entire process is provided separately (Supporting Information, Figure S7). The first step in this process is the removal of the lowestcoordinated $\mathrm{Cu}$ adatom from the corner position of the $\operatorname{Pt}(111)$ facet. The stripping energy, $E_{\text {strip }}$, for this step was calculated as $3.95 \mathrm{eV}$; subsequent stripping of $\mathrm{Cu}$ atoms from the $\operatorname{Pt}(111)$ facet (step 2) was found to be spontaneous (Supporting Information, Figure S7). Similarly, the energy required to remove the first $\mathrm{Cu}$ atom from the $\mathrm{Pt}(100)$ facet (step 3), $4.11 \mathrm{eV}$, was the most difficult and defines the position of the stripping peak. Converting these stripping energies to potentials gives calculated UPD shifts of 0.57 and $0.49 \mathrm{~V}$ for the stripping of $\mathrm{Cu}$ from the $\mathrm{Pt}(100)$ and $\mathrm{Pt}(111)$ facets of the $\mathrm{Pt}_{147} @ \mathrm{Cu}_{\text {full }}$ DFT model (Table 1). The difference between these peak positions, $\Delta V_{\text {strip }}{ }^{\mathrm{DFT}}=0.08 \mathrm{~V}$, is close to the experimental value of $0.14 \mathrm{~V}$ (Table 1 and Figure 4), but the magnitude of the UPD shift far exceeds the corresponding experimental values of 0.29 and $0.15 \mathrm{~V}$.

To better reconcile the experimental and theoretical findings, $\mathrm{SO}_{4}$ ligands were used to evaluate solvent interactions, thereby stripping $\mathrm{Cu}$ from the $\left(\mathrm{SO}_{4}\right) \mathrm{Pt}_{147} @ \mathrm{Cu}_{\text {full }}$ DFT-half model. Figure $5 \mathrm{~b}$ shows the key steps in the stripping process. The overall effect of the $\mathrm{SO}_{4}$ ligands is to reduce the binding energy of $\mathrm{Cu}$ by $\sim 0.5 \mathrm{eV}$. This constant reduction in binding energy can be understood as arising from saturation of the $\mathrm{Cu}$ dangling bonds and a subsequent weakening of the $\mathrm{Cu}-\mathrm{Cu}$ and $\mathrm{Cu}-\mathrm{Pt}$ interactions.

In the presence of $\mathrm{SO}_{4}$ ligands, the calculated UPD shifts for $\mathrm{Cu}$ stripping are calculated to be 0.33 and $0.25 \mathrm{~V}$ for the $\mathrm{Pt}(100)$ and $\mathrm{Pt}(111)$ facets, respectively. These potentials are much closer to the corresponding experimentally observed UPD shifts of 0.29 and $0.15 \mathrm{~V}$, illustrating the importance of ligand interactions.

In-Situ XAS Analysis of G6-OH( $\left.\mathrm{Pt}_{147} @ \mathrm{Cu}_{\text {full }}\right)$ and G6$\mathrm{OH}\left(\mathrm{Pt}_{147} @ \mathrm{Cu}_{\text {partial }}\right)$. We turned to in situ XAS to characterize the structures of G6-OH $\left(\mathrm{Pt}_{147} @ \mathrm{Cu}_{\text {full }}\right)$ and G6-OH( $\left(\mathrm{Pt}_{147} @\right.$ $\left.\mathrm{Cu}_{\text {partial }}\right)$ DENs so that these could be compared to the structural models predicted by DFT and MD simulations. Insitu characterization of these structures is necessary, because we found that $\mathrm{Cu}$ monolayers and submonolayers on Pt DENs are 
only stable in air, or at the OCP in solution, for $\sim 1 \mathrm{~min}$; however, the XAS spectra are acquired over a period of about $24 \mathrm{~h}$. The procedure used to carry out these spectroelectrochemical experiments was discussed in detail in the Experimental Section, but, briefly, dialyzed $\mathrm{G} 6-\mathrm{OH}\left(\mathrm{Pt}_{147}\right)$ DEN cores were immobilized on an AvCarb carbon-paper electrode and its potential was controlled during XAS data acquisition. The samples were characterized with the electrode poised at two potentials: $V_{\text {full, }}$ which corresponds to a full $\mathrm{Cu}$ UPD shell $\left(\mathrm{G} 6-\mathrm{OH}\left(\mathrm{Pt}_{147} @ \mathrm{Cu}_{\text {full }}\right)\right)$, and $V_{\text {partial, a potential }}$ positive of $V_{\text {full }}$ corresponding to a partial $\mathrm{Cu}$ shell (G6$\left.\mathrm{OH}\left(\mathrm{Pt}_{147} @ \mathrm{Cu}_{\text {partial }}\right)\right)$. The CNs obtained from fits to the XAS data can be compared to those calculated for a number of reasonable structural models, which are shown in Figure 6. The $\mathrm{CNs}$ calculated for the models are presented alongside the CNs extracted from the fits to the data (calculated and extracted, respectively, in Tables 2 and 3 ).

Table 2. CNs Extracted from Experimental, In-Situ XAS Spectra of G6-OH $\left(\mathrm{Pt}_{147} @ \mathrm{Cu}_{\mathrm{full}}\right)$ Compared to CNs Calculated from the Full-Coverage (F) Model Structures Shown in Figure 6

\begin{tabular}{|c|c|c|c|}
\hline $\begin{array}{l}\text { coordination no. } \\
\qquad(\mathrm{CN})^{a}\end{array}$ & $\begin{array}{l}\text { extracted } \mathrm{CN}^{c} \\
\text { (sample) }\end{array}$ & $\begin{array}{l}\text { calculated } \mathrm{CN}^{d} \\
(\text { model F1) }\end{array}$ & $\begin{array}{c}\text { calculated CN } \\
(\text { model F2) }\end{array}$ \\
\hline$n_{\mathrm{PP}}$ & $6.7 \pm 1.1$ & 8.9 & 6.9 \\
\hline$n_{\mathrm{PC}}$ & $2.4 \pm 0.8$ & 2.5 & 2.9 \\
\hline$n_{\mathrm{CC}}$ & $2.7 \pm 3.7$ & 2.8 & 3.1 \\
\hline$n_{\mathrm{CP}}$ & $3.9 \pm 0.2$ & 3.5 & 4.1 \\
\hline$n_{\mathrm{CO}}{ }^{b}$ & $0.7 \pm 0.4$ & $\mathrm{~N} / \mathrm{A}^{e}$ & $\mathrm{~N} / \mathrm{A}$ \\
\hline$n_{P m}$ & 9.1 & 11.4 & 7.8 \\
\hline$n_{C m}$ & 6.6 & 6.3 & 7.2 \\
\hline
\end{tabular}

${ }^{a} \mathrm{CN}$ is coordination number. ${ }^{b} n_{\mathrm{CO}}$ represents $\mathrm{Cu}$ with a low- $Z$ nearest-neighbor. ${ }^{c}$ Extracted $\mathrm{CN}$ is extracted from the fit to the data. ${ }^{d}$ Calculated $\mathrm{CN}$ is estimated from the referenced DFT model. ${ }^{e} \mathrm{~N} / \mathrm{A}$ meaning not applicable because we did not include low- $Z$ neighbors in the referenced models.

The radial distribution spectra of the XAS data and the computed fits for G6-OH $\left(\mathrm{Pt}_{147} @ \mathrm{Cu}_{\text {full }}\right)$ are shown in Figure 7a and $\mathrm{b}$ for the $\mathrm{Pt} \mathrm{L} 3$ and $\mathrm{Cu} \mathrm{K}$ absorbance edges, respectively. The $R$-space distribution and fits for G6-OH( $\left(\mathrm{Pt}_{147} @ \mathrm{Cu}_{\text {partial }}\right)$ are given in Figure $7 \mathrm{c}$ and d, and these also show both the $\mathrm{Pt}$ and $\mathrm{Cu}$ edge data, respectively. The corresponding $k$-space data are provided separately (Supporting Information, Figure S8).
The structure of the G6-OH $\left(\mathrm{Pt}_{147} @ \mathrm{Cu}_{\mathrm{full}}\right)$ DENs is determined by fitting the XAS data, as described in the Experimental Section and then comparing the extracted $\mathrm{CNs}$ to the $\mathrm{CNs}$ calculated for model F1 and model F2 (Table 2 and Figure 6).

The following CNs were extracted from the fits to the in situ XAS data and compared to CNs calculated for the models: $\mathrm{Pt}-$ Pt $\left(n_{\mathrm{PP}}\right), \mathrm{Pt}-\mathrm{Cu}\left(n_{\mathrm{PC}}\right), \mathrm{Cu}-\mathrm{Pt}\left(n_{\mathrm{CP}}\right), \mathrm{Cu}-\mathrm{Cu}\left(n_{\mathrm{CC}}\right), \mathrm{Pt}-\mathrm{m}$ $\left(n_{P m}\right)$, and Cu-m $\left(n_{C m}\right)$. Here, $\mathrm{m}$ is any metal (Pt or $\left.\mathrm{Cu}\right)$ that is coordinated to $\mathrm{Pt}$ or $\mathrm{Cu}$. The modeling approach assumes $n_{P m}$ $=n_{\mathrm{PP}}+n_{\mathrm{PC}}$ and $n_{\mathrm{Cm}}=n_{\mathrm{CC}}+n_{\mathrm{CP}}$. The values of $n_{\mathrm{Pm}}$ and $n_{\mathrm{Cm}}$ essentially represent how coordinatively saturated the Pt and $\mathrm{Cu}$ atoms are relative to each other, and these are used to draw conclusions about DEN structure. We also extracted another $\mathrm{CN}$ from the experimental results, $\mathrm{Cu}-\mathrm{O}$ (denoted $n_{\mathrm{CO}}$ ), where $-\mathrm{O}$ is a low- $z$ nearest neighbor (most likely $\mathrm{H}_{2} \mathrm{O}, \mathrm{HSO}_{4}{ }^{-}$, or $\mathrm{SO}_{4}{ }^{2-}$ ) on the $\mathrm{Cu}$ shell. ${ }^{41}$ It was necessary to include the $\mathrm{Cu}-\mathrm{O}$ scattering path to accurately fit the experimental data, but we did not calculate a $\mathrm{CN}$ corresponding to $n_{\mathrm{CO}}$ for the models in Figure 6 because low- $z$ neighbors were not included in these model structures.

Table 2 provides the extracted CNs for G6-OH( $\mathrm{Pt}_{147} @$ $\left.\mathrm{Cu}_{\text {full }}\right)$, as well as the calculated CNs for 2 full-shell models: model F1 and model F2 (Figure 6). Model F1 is the previously described $\mathrm{Pt}_{147} @ \mathrm{Cu}_{\text {full }}$ DFT model, in which $\mathrm{Cu}$ resides on the DEN facets. The structure represented by model F2 was constructed by performing MD simulations on model F1, and it shows the partial mixing of the $\mathrm{Cu}$ shell atoms with the Pt core.

The experimental value for $n_{\mathrm{Pp}}$ (Table 2) was extracted from the data taken with the electrode poised at $V_{\text {full }}$ and represents the average $\mathrm{Pt}-\mathrm{Pt} \mathrm{CN}$ for $\mathrm{G} 6-\mathrm{OH}\left(\mathrm{Pt}_{147} @ \mathrm{Cu}_{\text {full }}\right)$. We found that the extracted value for $n_{\mathrm{PP}}(\mathrm{CN}=6.7 \pm 1.1)$ is significantly lower than the calculated $n_{\mathrm{PP}}$ of model F1 $(\mathrm{CN}=8.9): n_{\mathrm{PP}}=$ 8.9 for a perfect 147 -atom, cuboctahedral Pt cluster. ${ }^{42}$ Although the extracted $n_{\mathrm{PP}}$ underestimates the ideal value for the 147atom $\mathrm{Pt}$ core, it is the same as the $n_{\mathrm{PP}}$ reported previously for $\mathrm{Pt}$ DENs of this size. ${ }^{27,28}$ There are several possible explanations for the discrepancy between the extracted and calculated $n_{\mathrm{PP}}$ values. First, we have previously shown that some $\mathrm{Pt}^{2+}$ remains within the dendrimer after reduction. ${ }^{28}$ This will result in a lower-than-expected value for $n_{\mathrm{PP}}$, because $n_{\mathrm{PP}}$ represents the ensemble average $\mathrm{Pt}-\mathrm{Pt} \mathrm{CN}$ for the entire sample and will therefore include contributions from both $\mathrm{Pt}$ atoms in the DENs and unreduced $\mathrm{Pt}^{2+}(\mathrm{CN}=0)$. To evaluate this possibility, we carried out XPS measurements on the Pt DENs used for the XAS analysis. The results of XPS measurements on

Table 3. CNs Extracted from Experimental, In-Situ XAS Spectra of G6-OH( $\left(\mathrm{Pt}_{147} @ \mathrm{Cu}_{\text {partial }}\right)$ Compared to CNs Calculated from the Partial (P) Model Structures Illustrated in Figure 6

\begin{tabular}{|c|c|c|c|c|c|c|}
\hline $\begin{array}{l}\text { coordination no. } \\
\qquad(\mathrm{CN})^{a}\end{array}$ & $\begin{array}{l}\text { extracted } \mathrm{CN}^{c} \\
\text { (sample) }\end{array}$ & $\begin{array}{l}\text { calculated } \mathrm{CN}^{d} \\
(\text { model P1) }\end{array}$ & $\begin{array}{l}\text { calculated CN } \\
(\text { model P2) }\end{array}$ & $\begin{array}{l}\text { calculated CN } \\
\text { (model P3) }\end{array}$ & $\begin{array}{l}\text { calculated CN } \\
\text { (model P4) }\end{array}$ & $\begin{array}{c}\text { calculated CN } \\
\text { (model P5) }\end{array}$ \\
\hline$n_{\mathrm{PP}}$ & $7.5 \pm 1.3$ & 8.9 & 8.9 & 8.9 & 8.9 & 8.9 \\
\hline$n_{\mathrm{PC}}$ & $1.8 \pm 0.7$ & 1.5 & 1.0 & 1.2 & 1.4 & 1.3 \\
\hline$n_{\mathrm{CC}}$ & $1.5 \pm 0.8$ & 2.7 & 3.0 & 2.8 & 19 & 1.1 \\
\hline$n_{\mathrm{CP}}$ & $4.9 \pm 0.7$ & 4.0 & 3.0 & 3.5 & 3.8 & 3.6 \\
\hline$n_{\mathrm{CO}}^{b}$ & $0.3 \pm 2.8$ & $\mathrm{~N} / \mathrm{A}^{e}$ & $\mathrm{~N} / \mathrm{A}$ & $\mathrm{N} / \mathrm{A}$ & $\mathrm{N} / \mathrm{A}$ & $\mathrm{N} / \mathrm{A}$ \\
\hline$n_{P m}$ & 9.3 & 10.4 & 9.9 & 10.1 & 10.3 & 10.2 \\
\hline$n_{\mathrm{Cm}}$ & 6.4 & 6.7 & 6.0 & 6.3 & 5.7 & 4.7 \\
\hline$R$-value ${ }^{f}$ & $\mathrm{~N} / \mathrm{A}^{g}$ & 4.4 & 6.9 & 5.6 & 3.8 & 4.2 \\
\hline
\end{tabular}

${ }^{a} \mathrm{CN}$ is coordination number. ${ }^{b} n_{\mathrm{CO}}$ represents $\mathrm{Cu}$ with a low- $\mathrm{Z}$ nearest-neighbor. ${ }^{c}$ Extracted $\mathrm{CN}$ is extracted from the fit to the data. ${ }^{d} \mathrm{Calculated}$ $\mathrm{CNs}$ are estimated from the referenced DFT models. ${ }^{e} n_{\mathrm{CO}}$ was not calculated because the concentration of low- $Z$ nearest-neighbors (E) adsorbed to $\mathrm{Cu}$ has not been measured on $\mathrm{Pt}_{147} @ \mathrm{Cu}$ structures. ${ }^{f_{\mathrm{T}}} \mathrm{Te} R$-value describes the correlation between the data and the referenced models. ${ }^{g}$ Not applicable because the $R$-value only applies to the models. 

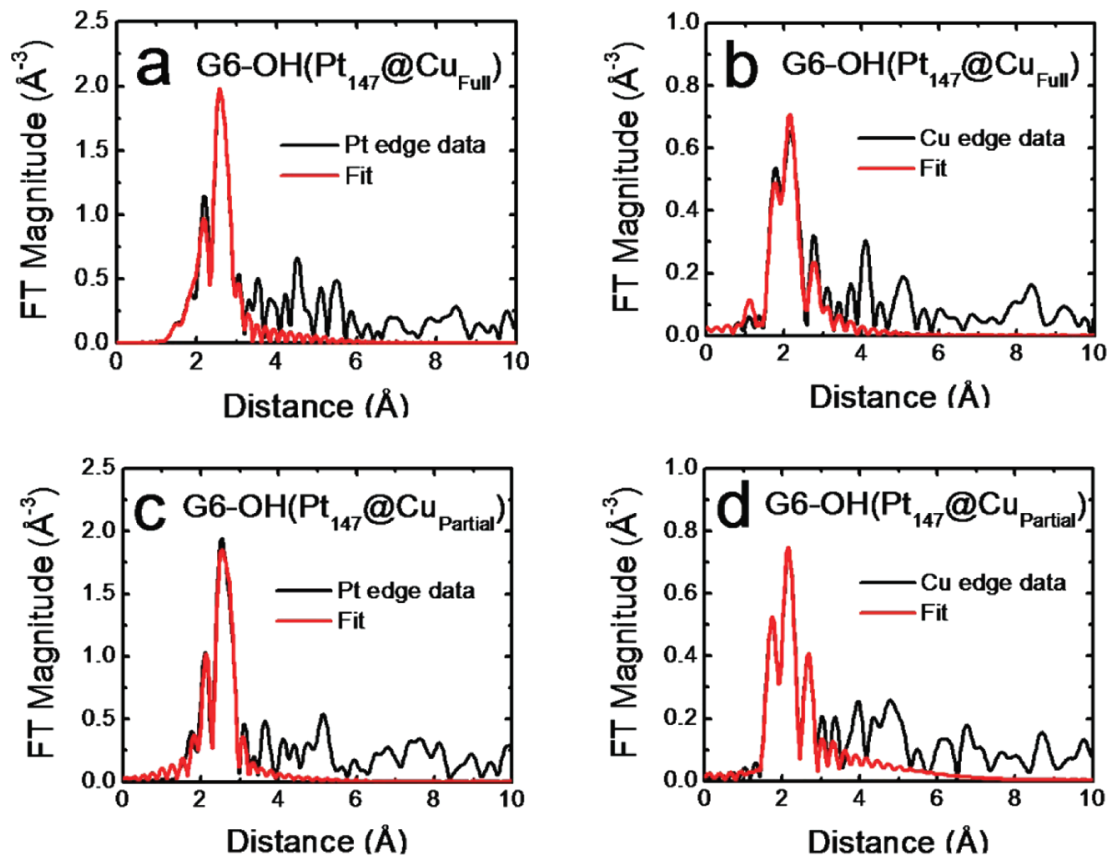

Figure 7. Radial distribution graphs of the in situ XAS data (black) and the computed fits (red) for (a and b) G6-OH( $\left.\mathrm{Pt}_{147} @ \mathrm{Cu}_{\text {full }}\right)$ and (c and d) $\mathrm{G} 6-\mathrm{OH}\left(\mathrm{Pt}_{147} @ \mathrm{Cu}_{\text {partial }}\right)$. These data were collected in a solution of $0.10 \mathrm{M} \mathrm{H}_{2} \mathrm{SO}_{4}$ with the electrode poised at $V_{\text {full }}$ and $V_{\text {partial }}$ for G6-OH(Pt $\left.\mathrm{Cu}_{\text {full }}\right)$ and G6-OH $\left(\mathrm{Pt}_{147} @ \mathrm{Cu}_{\text {partial }}\right)$, respectively.

the G6-OH( $\left(\mathrm{Pt}_{147} @ \mathrm{Cu}_{\text {full }}\right)$ confirmed the presence of a small fraction of unreduced $\mathrm{Pt}^{2+}$ (Supporting Information, Figure S9).

A second possible explanation for the lower-than-expected $n_{\mathrm{PP}}$ value could be partial alloying of some of the $\mathrm{Cu}$ shell atoms with the $\mathrm{Pt}$ atoms directly beneath them, as shown in model $\mathrm{F} 2$. As $\mathrm{Cu}$ atoms partition into the core, they displace some of the $\mathrm{Pt}$ atoms that reside in the first coordination shell of other Pt atoms, and therefore, on average, the $\mathrm{Pt}$ atoms in the DENs have fewer Pt nearest neighbors. However, we have made some observations which make it seem unlikely that model F2 is a viable representation of the actual DENs. Specifically, we noted earlier that the full $\mathrm{Cu}$ shell blocks $\mathrm{H}_{\text {UPD }}$ (Figure S5), which is not expected in the case of $\mathrm{PtCu}$ alloyed nanoparticles which have both $\mathrm{Pt}$ and $\mathrm{Cu}$ on their surfaces. With regard to this point, Strasser and co-workers ${ }^{37}$ and Stevenson and co-workers ${ }^{38}$ have shown that $\mathrm{H}_{\text {UPD }}$ does occur on $\mathrm{PtCu}$ alloy nanoparticles having just a fractional coverage of $\mathrm{Pt}$ atoms on the surface. Therefore, we believe that the blocking of $\mathrm{H}_{\mathrm{UPD}}$ on the G6-OH( $\left.\mathrm{Pt}_{147} @ \mathrm{Cu}_{\text {full }}\right)$ DENs provides good evidence that the $\mathrm{Pt}$ atoms in our DENs remain beneath the $\mathrm{Cu}$ shell and do not partition to the surface as depicted in model F2.

The extracted CNs for $n_{\mathrm{PC}}, n_{\mathrm{CP}}$, and $n_{\mathrm{CC}}$ are all in reasonable agreement with the values predicted for both the F1 and F2 models. However, from a modeling perspective, there are a few clear trends that distinguish core@shell nanoparticles from random atomic arrangements, such as alloys. For example, the value of $n_{C m}$ will be less than $n_{P m}$ for a core@shell particle, because $\mathrm{Cu}$ atoms confined to the surface of the nanoparticle will have fewer nearest neighbors than those occupying coordinatively saturated positions in the core. ${ }^{43}$ We find that $n_{P m}$ is larger than $n_{C m}$ (Table 2) both for the experimentally extracted $\mathrm{CNs}$ and also for the CNs calculated for each of the models. Therefore, we postulate that the true structure of G6$\mathrm{OH}\left(\mathrm{Pt}_{147} @ \mathrm{Cu}_{\text {full }}\right)$ has a Pt rich core and a Cu-rich shell. As mentioned earlier, even though the partially alloyed model is well matched to the XAS data, electrochemical experiments show that the $\mathrm{Cu}$ shell completely passivates the Pt surface against $\mathrm{H}_{\mathrm{UPD}}$, and thus, we conclude that model $\mathrm{F} 1$ is the most viable of the full shell models.

The bond distances and Debye-Waller factors for G6$\mathrm{OH}\left(\mathrm{Pt}_{147} @ \mathrm{Cu}_{\text {full }}\right)$ are provided in Table S1 in the Supporting Information. The Debye-Waller factors indicate greater disorder in all of the $\mathrm{Cu}-\mathrm{m}$ bond pairs $\left(n_{\mathrm{CC}}, n_{\mathrm{CP}}\right)$ compared to $\mathrm{Pt}-\mathrm{Pt}$ bonds. This is indicative of segregation of the core and shell phases, because the atoms on the surface are considered to occupy high energy defect positions and tend to exhibit greater disorder than the coordinatively saturated atoms nearer the core. ${ }^{5,28}$ The average $\mathrm{Pt}-\mathrm{Pt}$ bond distance $(2.74 \AA$ ) is shorter than that of bulk Pt $(2.77 \AA)$. The contractile straining of the core phase may be attributed to surface tension. ${ }^{44}$ The experimentally determined $\mathrm{Cu}-\mathrm{Cu}$ bond distance $(2.68 \AA)$ exhibits a tensile strain due to lattice mismatch with the underlying $\mathrm{Pt}$ lattice. $\mathrm{Cu}$ monolayers on $\mathrm{Pt}$ will be template by the underlying Pt lattice, which has a larger lattice constant, and so the $\mathrm{Cu}-\mathrm{Cu}$ bond distance is expanded.

The CNs extracted from the fits to the XAS data for G6$\mathrm{OH}\left(\mathrm{Pt}_{147} @ \mathrm{Cu}_{\text {partial }}\right)$ DENs are presented in Table 3 alongside the CNs for the partial shell model structures depicted in Figure 6. The bond lengths and Debye-Waller factors are provided separately (Supporting Information, Table S2). Reassuringly, $n_{\mathrm{PP}}$ is about the same regardless of whether there is a partial $\left(n_{\mathrm{PP}}=7.5 \pm 1.3\right)$ or full $\left(n_{\mathrm{PP}}=6.7 \pm 1.1\right) \mathrm{Cu}$ shell present on the Pt core. The calculated $\mathrm{CNs}$ for the model structures (P1-P5, Figure 6) can be compared to the extracted CNs for the G6-OH( $\left(\mathrm{Pt}_{147} @ \mathrm{Cu}_{\text {partial }}\right)$ DENs. Model P1 is the most likely partial shell model according to the DFT calculations, which preferentially positions the partial-shell $\mathrm{Cu}$ atoms on the $\mathrm{Pt}(100)$ facets. Model P2 illustrates the opposite case, in which $\mathrm{Cu}$ decorates the $\mathrm{Pt}(111)$ facets. Model P3 is a partial shell model in which the $\mathrm{Cu}$ shell exhibits Janus-like 
coverage. On the basis of the experimental data and DFT calculations presented earlier, which served to demonstrate facet-selective $\mathrm{Cu}$ UPD behavior, it is unlikely that models P2 and P3 are correct, but we include them here for completeness.

Model P4 was constructed from model P1 by removing a few of the $\mathrm{Cu}$ atoms from the $\mathrm{Pt}(100)$ facets and placing them on $\mathrm{Pt}(111)$ facets. This could be a viable structure, because CV peaks for Cu UPD and stripping on the DENs (Figure 2, red line) overlap, indicating that stripping of the $\mathrm{Cu}$ atoms from one facet might not be complete before stripping from the other facet commences. In other words, some $\mathrm{Cu}$ atoms would still remain to be stripped from the $\operatorname{Pt}(111)$ facet when $\mathrm{Cu}$ atoms begin to strip from the $\mathrm{Pt}(100)$ facet. Model P5 is a partial shell model in which the $\mathrm{Cu}$ atoms are randomly distributed on the surface with no preference for one facet over the other. This model is an unlikely candidate, because it is incompatible with the results of our DFT studies, yet it was also included for comparison.

To determine which model provides the most favorable comparison to the experimental data, we calculated a correlation factor based on the calculated and extracted CNs and expressed this as the $R$-value in Table 3. The $R$-value, which is defined as the sum of the magnitude of differences between the extracted and calculated CNs, is used here to compare the models to the data, and to each other, to determine which model most closely approaches the experimentally characterized structure. The $R$-value was calculated according to eq 1 .

$$
R \text {-value }=\sum_{C N} \sqrt{\left(\frac{\mathrm{CN}_{\text {extracted }}-\mathrm{CN}_{\text {calculated }}}{\sigma}\right)^{2}}
$$

Here, $\mathrm{CN}_{\text {extracted }}$ values are $\mathrm{CNs}$ that were extracted from the fit to the data $\left(n_{\mathrm{pp}}, n_{\mathrm{PC}}, n_{\mathrm{CC}}\right.$, and $\left.n_{\mathrm{CP}}\right)$ ("Extracted" in Table 3 ) and $\mathrm{CN}_{\text {calculated }}$ values are the corresponding $\mathrm{CNs}$ for the model structures, and $\sigma$ is the standard deviation for the extracted CNs. A lower correlation factor means a lesser overall magnitude of difference across all the CNs for the sample and the model and thus a better overall fit. This approach is exactly analogous to the sum of standardized $z$-scores in statistical analysis. The $R$-value for model P4 (3.8) (Table 3) was the lowest, and therefore, model P4 provides the best structural comparison to the experimental data. This model (P4) is in good agreement with our DFT studies, which showed that the stripping of the $\mathrm{Cu}$ from the $\mathrm{Pt}(100)$ facet did, in fact, commence before all of the $\mathrm{Cu}$ had stripped from the $\mathrm{Pt}$ (111) facet (Supporting Information, Figure S7), and thus, it is highly likely that this model could be close to the structure of the G6-OH $\left(\mathrm{Pt}_{147} @ \mathrm{Cu}_{\text {partial }}\right)$ DENs that were characterized by in situ XAS. Our earlier studies of $\mathrm{H}_{\mathrm{UPD}}$ on G6-OH( $\mathrm{Pt}_{147} @$ $\left.\mathrm{Cu}_{\text {partial }}\right)$ also support the facet-selective $\mathrm{Cu}$ UPD mechanism (Supporting Information, Figure S5b).

The analysis of XAS data corresponding to G6-OH( $\mathrm{Pt}_{147} @$ $\left.\mathrm{Cu}_{\text {full }}\right)$ and $\mathrm{G6}-\mathrm{OH}\left(\mathrm{Pt}_{147} @ \mathrm{Cu}_{\text {partial }}\right)$ DENs suggests that $\mathrm{Cu}$ preferentially deposits on the $\mathrm{Pt}(100)$ facets: $n_{\mathrm{CP}}$ for G6$\mathrm{OH}\left(\mathrm{Pt}_{147} @ \mathrm{Cu}_{\text {partial }}\right)$ is close to 4, which would be the expected $\mathrm{CN}$ for $\mathrm{Cu}$ atoms residing in the 4-fold hollow positions. This is in agreement with XAS studies of $\mathrm{Cu}$ UPD on bulk Pt(100) single crystals. That is, $\mathrm{Cu}$ deposition is preferential for the $\mathrm{Pt}(100)$ orientation over the $\mathrm{Pt}(111)$ orientation. ${ }^{9}$

\section{SUMMARY AND CONCLUSIONS}

DENs are good model structures for comparing theory and experiment, because they are large enough to characterize experimentally but small enough to apply first-principles calculations. The present study represents our first effort to reconcile theory and experiment using a single model nanoparticle. Specifically, Pt DENs consisting of an average of 147 atoms and having a cuboctahedral structure were characterized in the presence and absence of full and partial monatomic $\mathrm{Cu}$ shells. Experimental observations by XPS, electrochemical methods, and in situ XAS were correlated to DFT calculations, and the results strongly suggest that $\mathrm{Cu}$ deposits primarily onto the $\mathrm{Pt}(100)$ facets of the DENs before deposition begins on the $\mathrm{Pt}(111)$ facets (Figure 6, model P4). This finding is consistent with previously reported results for $\mathrm{Cu}$ UPD onto bulk Pt single crystal electrodes. ${ }^{8-10}$ Perhaps the most meaningful result of the DFT studies was the finding that the presence of adsorbed $\mathrm{SO}_{4}$ ligands produces results that compare more favorably to the experimental data than do the simple, naked DENs.

We are now turning our attention to a more complicated problem: the effect of full and partial UPD layers on electrocatalytic reactions. By decorating particular facets of DEN electrocatalysts with UPD layers, we hope to be able to influence the rates of reactions, such as the ORR, that are known to have crystallographic preferences. We are also quite interested in correlating theoretical and experimental results for core@shell DENs having full outer shells to better understand how the core influences catalytic reactions occurring on the shell metal. Findings for these studies will be reported in due course.

\section{ASSOCIATED CONTENT}

\section{S Supporting Information}

A photograph of the electrochemical flow cell; cyclic voltammograms demonstrating the operation of the flow cell, oxidation of full and partial Cu UPD layers from Pt DENs, the hydrogen activity of Pt DENs with and without Cu UPD layers; TEM characterization of the Pt DENs; detailed view of the calculated UPD and stripping processes on naked and $\mathrm{SO}_{4}$ coated Pt nanoparticles; $k$-space XAS data; XPS results obtained from Pt DENs; and tables of EXAFS results. This material is available free of charge via the Internet at http:// pubs.acs.org.

\section{AUTHOR INFORMATION}

\section{Corresponding Author}

crooks@cm.utexas.edu; henkelman@mail.utexas.edu

Notes

The authors declare no competing financial interest.

\section{ACKNOWLEDGMENTS}

We gratefully acknowledge support from the Chemical Sciences, Geosciences, and Biosciences Division, Office of Basic Energy Sciences, Office of Science, U.S. Department of Energy (Contract: DE-FG02-09ER16090). R.M.C. thanks the Robert A. Welch Foundation (Grant F-0032) for sustained support. We also thank Prof. Anatoly I. Frenkel (Yeshiva University), Dr. Nebjosa Marinkovic (Brookhaven National Laboratory), Dr. Syed Khalid (Brookhaven National Laboratory), and David F. Yancey (UT-Austin) for assistance with the XAS studies. V. Sue Myers and Dr. Hugo Celio assisted 
with XPS measurements. Dr. J. P. Zhou (UT-Austin) assisted with the TEM measurements. G.H. would like to acknowledge support from the Robert A. Welch Foundation (Grant F-1601) and the W. A. "Tex" Moncrief, Jr. Endowment In SimulationBased Engineering Sciences through Grand Challenge Faculty Fellowships from the Institute of Computational and Engineering Sciences at The University of Texas at Austin. The computational work was done primarily at the National Energy Research Scientific Computing Center and the Texas Advanced Computing Center. Use of the NSLS was supported by the U.S. Department of Energy, Office of Science, Office of Basic Energy Sciences, under Contract No. DE-AC02-98CH10886. Beamline $\mathrm{X} 18 \mathrm{~B}$ at the NSLS is supported in part by the Synchrotron Catalysis Consortium, U.S. Department of Energy Grant No DE-FG02-05ER15688.

\section{REFERENCES}

(1) Scott, R. W. J.; Wilson, O. M.; Crooks, R. M. J. Phys. Chem. B 2005, 109, 692-704.

(2) Bronstein, L. M.; Shifrina, Z. B. Chem. Rev. 2011, 111, 53015344

(3) Myers, S. V.; Weir, M. G.; Carino, E. V.; Yancey, D. F.; Pande, S.; Crooks, R. M. Chem. Sci. 2011, 2, 1632-1646.

(4) Yancey, D. F.; Carino, E. V.; Crooks, R. M. J. Am. Chem. Soc. 2010, 132, 10988-10989.

(5) Carino, E. V.; Crooks, R. M. Langmuir 2011, 27, 4227-4235.

(6) Martin, T. P.; Bergmann, T.; Göhlick, H.; Lange, T. J. Phys. Chem. 1991, 95, 6421-6429.

(7) Danilov, A. I.; Nazmutdinov, R. R.; Zinkicheva, T. T.; Molodkina, E. B.; Rudnev, A. V.; Polukarov, Y. M.; Feliu, J. M. Russ. J. Electrochem. 2008, 44, 697-708.

(8) Gómez, R.; Feliu, J. M.; Abruña, H. D. Langmuir 1994, 10, 43154323.

(9) Herrero, E.; Buller, L. J.; Abruña, H. D. Chem. Rev. 2001, 101, 1897-1930.

(10) Francke, R; Climent, V.; Baltruschat, H.; Feliu, J. M. J. Electroanal. Chem. 2008, 624, 228-240.

(11) Scortichini, C. L.; Reilley, C. N. J. Electroanal. Chem. 1983, 152, 255-260.

(12) Nishihara, C.; Nozoye, H. J. Electroanal. Chem. 1995, 396, 139142.

(13) Buller, L. J.; Herrero, R.; Gómez, R.; Feliu, J. M.; Abruña, H. D. J. Phys. Chem. B 2000, 104, 5932-5939.

(14) Abdelmeguid, E. A.; Berenz, P.; Baltruschat, H. J. Electroanal. Chem. 1999, 467, 50-59.

(15) Rudnev, A. V.; Molodkina, E. B.; Danilov, A. I.; Polukarov, Y. M.; Feliu, J. M. Electrochem. Commun. 2008, 10, 502-505.

(16) Adzic, R. R.; Zhang, J.; Sasaki, K.; Vukmirovic, M. B.; Shao, M.; Wang, J. X.; Nilekar, A. U.; Mavrikakis, M.; Valerio, J. A.; Uribe, F. Top. Catal. 2007, 46, 249-262.

(17) Yu, Y.; Hu, Y.; Liu, X.; Deng, W.; Wang, X. Electrochim. Acta 2009, 54, 3092-3097.

(18) Jin, Y.; Shen, Y.; Dong, S. J. Phys. Chem. B 2004, 108, 81428147.

(19) Sasaki, K.; Mo, Y.; Wang, J. X.; Balasubramanian, M.; Uribe, F.; McBreen, J.; Adzic, R. R. Electrochim. Acta 2003, 48, 3841-3849.

(20) Sasaki, K.; Wang, J. X.; Naohara, H.; Marinkovic, N.; More, K.; Inada, H.; Adzic, R. R. Electrochim. Acta 2009, 55, 2645-2652.

(21) Wang, J. X.; Inada, H.; Wu, L.; Zhu, Y.; Choi, Y.; Liu, P.; Zhou, W.-P.; Adzic, R. R. J. Am. Chem. Soc. 2009, 131, 17298-17302.

(22) Lee, J.; Hwang, S.; Hongii, L.; Kwak, J. J. Phys. Chem. B 2004, $108,5372-5379$.

(23) Guerrini, L.; Lopez-Tobar, E.; Garcia-Ramos, J. V.; Domingo, C.; Sanchez-Cortes, S. Chem. Commun. 2011, 47, 3174-3176.

(24) Rodríguez-López, M.; Solla-Gullón, J.; Herrero, E.; Tuñón, P.; Feliu, J. M.; Aldaz, A.; Carrasquillo, A. J. Am. Chem. Soc. 2010, 132, $2233-2242$.
(25) Ye, H.; Crooks, R. M. J. Am. Chem. Soc. 2005, 127, 4930-4934. (26) Ye, H.; Crooks, J. A.; Crooks, R. M. Langmuir 2007, 23, 1190111906.

(27) Weir, M. G.; Myers, V. S.; Frenkel, A. I.; Crooks, R. M. ChemPhysChem 2010, 11, 2942-2950.

(28) Knecht, M. R.; Weir, M. G.; Myers, V. S.; Pyrz, W. D.; Ye, H.; Petkov, V.; Buttrey, D. J.; Frenkel, A. I.; Crooks, R. M. Chem. Mater. 2008, 20, 5218-5228.

(29) Kiema, G. K.; Aktay, M.; McDermott, M. T. J. Electroanal. Chem. 2003, 540, 7-15.

(30) Newville, M. J. Synchrotron Radiat. 2001, 8, 322-324.

(31) Ravel, B.; Newville, M. J. Synchrotron Radiat. 2005, 12, 537541.

(32) Ravel, B. J. Synchrotron Radiat. 2001, 8, 314-316.

(33) Kresse, G.; Furthmuller, J. Comput. Mater. Sci. 1996, 6, 15-50.

(34) Kresse, G.; Furthmuller, J. Phys. Rev. B 1996, 54, 11169-11186.

(35) Perdew, J. P.; Wang, Y. Phys. Rev. B 1992, 45, 13244-13249.

(36) Plimpton, S. J. Comput. Phys. 1995, 117, 1-19.

(37) Mani, P.; Srivastava, R.; Strasser, P. J. Phys. Chem. C 2008, 112, 2770-2778

(38) Gupta, G.; Slanac, D. A.; Kumar, P.; Wiggins-Camacho, J. D.; Wang, X.; Swinnea, S.; More, K. L.; Dai, S.; Stevenson, K. J.; Johnston, K. P. Chem. Mater. 2009, 21, 4515-4526.

(39) Kolb, D. M.; Przasnyski, M.; Gerischer, H. Surf. Sci. 1974, 43, 662-666.

(40) Kolb, D. M.; Przasnyski, M.; Gerischer, H. J. Electroanal. Chem. 1974, 54, 25-38.

(41) Yee, H. S.; Abruña, H. D. J. Phys. Chem. 1994, 98, 6552-6558.

(42) Glasner, D.; Frenkel, A. I. XAFS 13, Proc. Int. Conf. X-ray Absorpt. Fine Struct. 2007, 882, 746-748.

(43) Weir, M. G.; Knecht, M. R.; Frenkel, A. I.; Crooks, R. M. Langmuir 2010, 26, 1137-1146.

(44) Mavrikakis, M.; Hammer, B.; Nørskov, J. K. Phys. Rev. Lett. 1998, 81, 2819-2822. 